\title{
Performance Metrics Research Project - Final Report
}

Technical Report NREL/TP-550-38700

October 2005

M. Deru and P. Torcellini

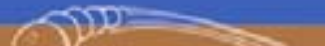




\section{Performance Metrics Research Project - Final Report}

Technical Report NREL/TP-550-38700 October 2005

M. Deru and P. Torcellini

Prepared under Task No. BEC3.3003

National Renewable Energy Laboratory 1617 Cole Boulevard, Golden, Colorado 80401-3393 303-275-3000 • www.nrel.gov

Operated for the U.S. Department of Energy

Office of Energy Efficiency and Renewable Energy

by Midwest Research Institute - Battelle

Contract No. DE-AC36-99-G010337

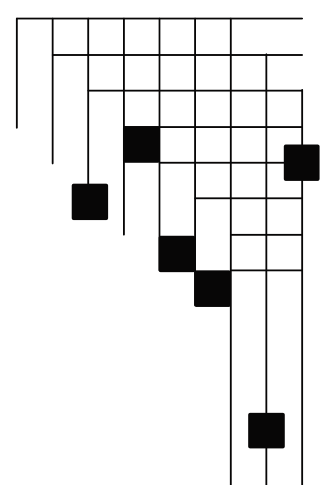




\section{NOTICE}

This report was prepared as an account of work sponsored by an agency of the United States government. Neither the United States government nor any agency thereof, nor any of their employees, makes any warranty, express or implied, or assumes any legal liability or responsibility for the accuracy, completeness, or usefulness of any information, apparatus, product, or process disclosed, or represents that its use would not infringe privately owned rights. Reference herein to any specific commercial product, process, or service by trade name, trademark, manufacturer, or otherwise does not necessarily constitute or imply its endorsement, recommendation, or favoring by the United States government or any agency thereof. The views and opinions of authors expressed herein do not necessarily state or reflect those of the United States government or any agency thereof.

Available electronically at http://www.osti.gov/bridge

Available for a processing fee to U.S. Department of Energy and its contractors, in paper, from:

U.S. Department of Energy

Office of Scientific and Technical Information

P.O. Box 62

Oak Ridge, TN 37831-0062

phone: 865.576 .8401

fax: 865.576 .5728

email: mailto:reports@adonis.osti.gov

Available for sale to the public, in paper, from:

U.S. Department of Commerce

National Technical Information Service

5285 Port Royal Road

Springfield, VA 22161

phone: 800.553 .6847

fax: 703.605.6900

email: orders@ntis.fedworld.gov

online ordering: http://www.ntis.gov/ordering.htm 


\section{Acknowledgments}

The authors would like to thank the following people at DOE for starting and providing leadership for this project: Drury Crawley, David Hansen, John Ryan, and Terry Logee. This project would not have been successful without all the hard work put in by the following people: Sheila Hayter, Dennis Barley, Shanti Pless, Nathan Blair, and Lauren Poole at NREL; Joel Ann Todd of Scientific Consulting Group; and Ed Hancock of Mountain Energy Partnership. 


\section{Table of Contents}

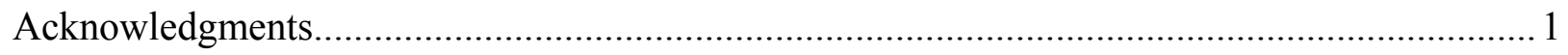

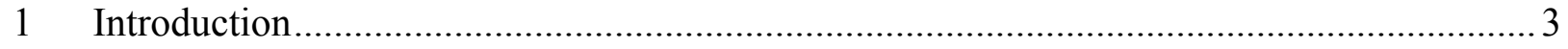

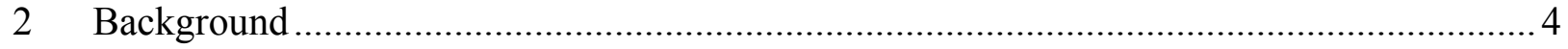

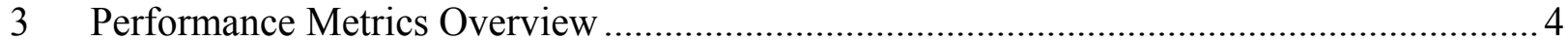

What Is a Metric? ............................................................................................. 5

3.2 Who Uses Metrics and How Are They Used? .................................................. 5

4 Performance Metrics Research Project Results ...................................................... 7

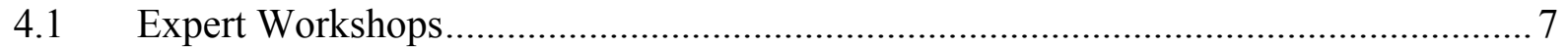

4.2 Significant Metrics for Measuring Performance........................................................ 8

4.3 Work with Related Activities............................................................................ 9

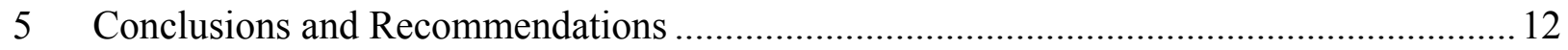

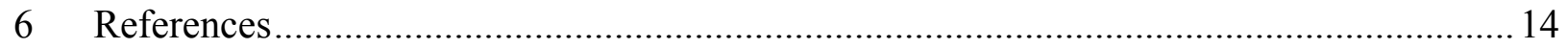

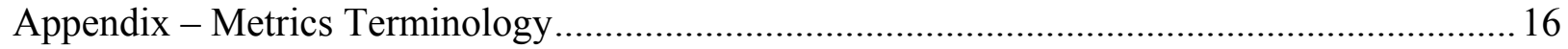




\section{Introduction}

There are numerous efforts to increase the energy efficiency and sustainability of commercial buildings and many approaches to measure the performance of buildings. Much of the credit for advancement in building performance goes to the U.S. Department of Energy (DOE) research efforts. DOE has set very aggressive goals for building research over the next 20 years, yet we do not have consistent methods of measuring the progress toward these goals. The National Renewable Energy Laboratory (NREL) began work for DOE on the Performance Metrics Research Project to standardize the measurement and characterization of building energy performance. NREL's primary research objectives were to determine which performance metrics have the greatest value for determining energy performance and to develop standard definitions and methods of measuring and reporting that performance.

NREL conducted this research over a five-year period, which began with an extensive review of existing metrics (see Background). The Overview section defines what metrics are, how they are used, and who uses them. It outlines critical issues in the definition and use of building energy performance metrics. In addition, it provides guidance on how to use performance metrics within a building project as well as a glossary of metrics terminology. The Project Results section discusses the activities undertaken by NREL and describes the products produced by the project. Conclusions and recommendations for future research are included at the end.

Many groups will benefit from this research, but our primary audience is users with a technical background in building energy performance. This group includes building science researchers and building energy service professionals. Other users with a higher level interest in building performance will also benefit directly from this project and from derivative products developed in the future. The approach to defining performance metrics and the methods developed for monitoring projects in these procedures can be extended to other areas of building performance. 


\section{Background}

The need to establish standardized building performance metrics and procedures for determining them was identified as one of four priority activities in the joint DOE/building industry High Performance Commercial Building Roadmap (DOE 2000). According to the roadmap, one of the core challenges to achieving widespread adoption of high-performance buildings is to determine which performance metrics are of greatest value to the building community and then to determine the most reliable ways to measure and report them.

One problem in evaluating building energy performance has been the inconsistency in approaches and terminology. If you ask 10 energy professionals to give you the energy performance of a building, you will probably get 10 different answers. This happens because engineers have their own methods for defining and determining energy performance. Some efforts in recent years stand out as significant contributions to monitoring, analyzing, and reporting building energy performance. The American Society of Heating, Refrigerating, and Air-Conditioning Engineers (ASHRAE) Guideline 14, Measurement of Energy and Demand Savings, presents a detailed description of procedures for measuring and reporting energy and demand savings (ASHRAE 2002). AHSRAE Standard 105, Standard Methods for Measuring, Reporting, and Comparing Building Energy Performance, is under revision and expected to be completed in 2006 (ASHRAE 1999). The International Performance Measurement and Verification Protocol (IPMVP) group has developed a series of protocols for measurement and verification projects (IPMVP 2005). Much of the foundation for the ASHRAE and IPMVP publications was developed by Texas A\&M University through the LoneSTAR project, which developed energy monitoring guidelines for use in Texas (Haberl et al. 1992 and Haberl et al. 1996). The U.S. Environmental Protection Agency's (EPA) ENERGY STAR ${ }^{\circledR}$ program has created the Portfolio Manager as another rating tool used by the industry for determining energy performance (EPA 2005). The U.S. Green Building Council (USGBC) continues to improve its widely used Leadership in Energy and Environmental Design (LEED) rating systems for promoting sustainable building design (USGBC 2005). However, LEED does not offer methods for measuring or analyzing energy performance and refers to ASHRAE and the EPA for this information. Yet, even with all this activity, there is still a lack of consensus in the definition of terms and performance metrics. If the building industry is to accept energy efficiency processes and materials, they must be provided reliable data. This project is an attempt to remedy the "metrics problem" by providing consensus to the industry on metric definitions and the methods used to determine energy performance.

\section{Performance Metrics Overview}

We started this project with a review of performance metrics and methods used to evaluate building energy performance. This effort continued throughout the project and is presented in our report Review of Building Energy Performance Metrics (Deru and Todd 2004).

This section provides information about how we evaluated the state-of-the science for evaluating building energy performance. It defines the term performance metrics for this research, why they are used, who uses them, and how they are used. 


\subsection{What Is a Metric?}

There is often confusion about the term performance metric. A metric is a standard definition of any measurable quantity, and a performance metric is a standard definition of a measurable quantity that indicates some aspect of performance. Many other terms are used with a similar meaning, such as performance indicator, performance index, and benchmarking. Definitions for these and other terms are included in Appendix A.

Performance metrics need certain characteristics to be valuable and practical. A performance metric should:

- Be measurable (or able to be determined from other measurements).

- Have a clear definition, including boundaries of the measurements.

- Indicate progress toward a performance goal.

- Answer specific questions about the performance.

There is often confusion with how the term performance metric is used. It is often used to mean a performance objective or goal. We have defined performance objective to mean a general statement of the desired achievement, and a performance goal is a specific statement of the desired level of achievement. Performance objectives are broad statements, such as "minimize primary energy consumption," whereas performance goals are specific and measurable, such as "reduce primary energy consumption for building operations by $30 \%$ compared to that consumed in 1990." There is an important relationship between these terms, which is discussed in the next section.

\subsection{Who Uses Metrics and How Are They Used?}

Over the lifetime of buildings, several groups measure and analyze the energy performance for many reasons. Policy makers, owners, designers, operators, raters, and researchers all use some form of energy performance data. Comparisons of energy use may be made among nations, regions, buildings, or systems within a building. However, methods and metrics used for comparisons are often inconsistent with each other. In addition, performance numbers are sometimes misrepresented or misused to predict energy savings beyond their accuracy.

One objective of this project was to provide consistency in how building performance metrics are determined and reported. Our intention is that data collection and analysis are accurate and not intentionally or unintentionally biased and that performance metrics provide an accurate, standardized reporting of energy performance data so that we can compare "apples to apples." Clear, consistent, and accurate performance metrics help researchers understand what drives building energy performance, help designers and owners build and operate more efficient buildings, and help policy makers formulate meaningful performance goals and track progress toward those goals.

To improve usability by a broad range of users, we defined two levels or tiers of performance metrics that can be used from the design stage through the operational life of a building. Tier 1 provides a high level view of building performance and can be derived from monthly and annual data such as those on utility bills. Tier 2 provides a detailed breakdown of the energy use and typically requires hourly or subhourly submetering. Performance indicators are above Tier 1 metrics, and they aggregate complex information to show planning level trends toward goals. 
Figure 1 presents a graphical view of the users of performance metrics and how this research supports them.

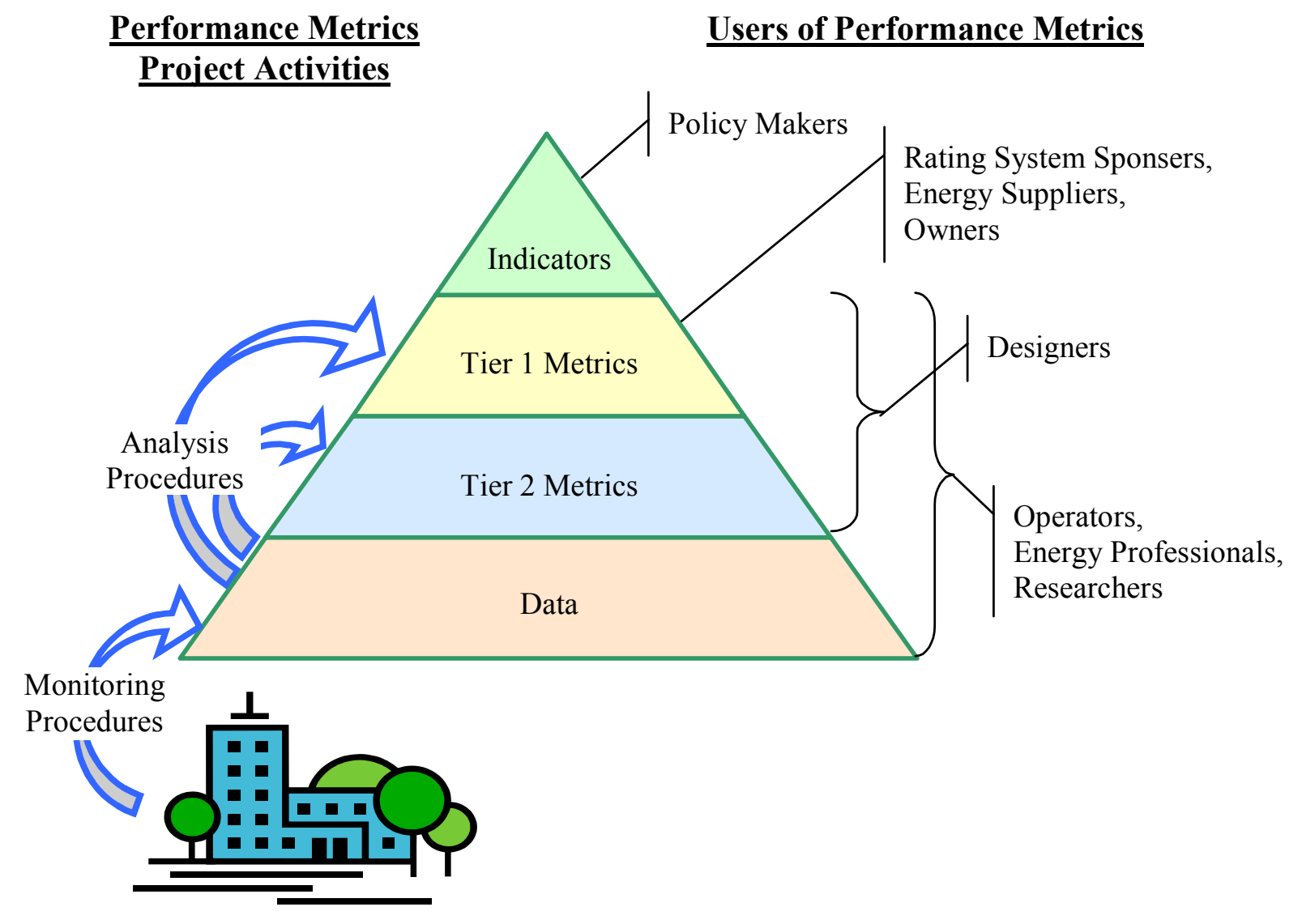

Figure 1 Overview of building performance evaluation

Performance metrics should be consistent with the performance objectives and performance goals of the projects. Performance metrics can be used with existing buildings or new building projects. Performance evaluation of existing buildings should start with a list of objectives. These objectives can be stated as questions about the performance. Performance metrics should be selected to answer these questions. The performance metrics must be directly related to the performance objectives. If the performance of the building is to be tracked or improved, specific performance goals should be set and performance metrics selected to measure progress toward the performance goals (Deru and Torcellini 2004).

New building projects should start with a vision statement. The project can be divided into topical areas with performance objectives. The performance objectives should then be stated as specific performance goals that the whole design team agrees on. The performance goals will be used to drive the design to get the desired result. Performance metrics are used to measure and track progress toward the performance goals. An example of how these terms are related is shown in Figure 2 (Deru and Torcellini 2004). 


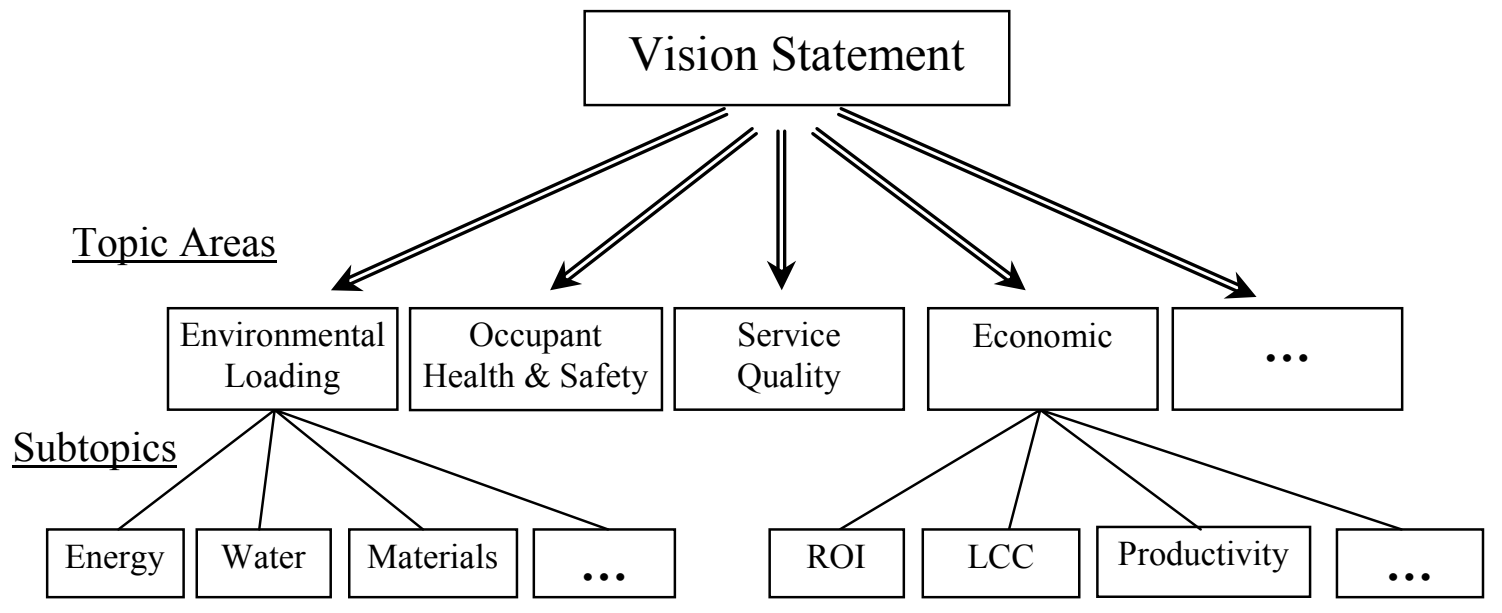

Energy Subtopic

Objective: Minimize source energy consumption for building operations.

Goal: Reduce annual source energy consumption by $70 \%$ compared to an energy code compliant building using ASHRAE 90.1 and a typical weather year.

Performannce Metrcs: Net Source Energy Use Intensity, Percent Savings Compared to ASHRAE 90.1-2001 Benchmark.

\section{Materials Subtopic}

Objective: Minimize construction and demolition waste going to landfill disposal.

Goal: Recycle and /or salvage at least $50 \%$ by weight of construction, demolition, and land clearing waste (USGBC 2004).

Performannce Metrcs: Percent construction material waste sent to recycling, percent of demolition material recovered for reuse or recycling.

Figure 2 Schematic of how performance metrics should be used in building projects

\section{Performance Metrics Research Project Results}

We started this project by gathering information about building performance evaluation from our own experience, literature reviews, current practices, and expert workshops. The original objective was to bring together the diverse approaches and try to find a common framework that could be applied to all building performance evaluation activities. In the end, the diversity of approaches and needs of each activity proved to be too large, and we decided to focus only on metrics and procedures for determining energy performance.

\subsection{Expert Workshops}

At DOE's direction, NREL organized and hosted two expert workshops at the outset of this project. The purpose of the workshops was to bring together experts in the area of building performance evaluation and provide input to the scope and direction for the Performance Metrics Research Project. The workshops were not limited to energy performance and included experts 
in all areas of building performance. More than 25 experts in building energy performance, environmental issues, worker productivity, psychological aspects of the built environment, and building economics attended the workshops. Attendees represented private- and public-sector entities in the United States and Canada.

The first workshop was held in Vail, Colorado, in November 2001; the second was held in Park City, Utah, in May 2002. During the workshops, small groups were formed in five areas of building performance: energy consumption, resource consumption and environmental loadings not associated with building energy use, human factors, economics, and service quality. Reports from the workshops are available from the project Web site http://www.eere.energy.gov/buildings/highperformance/performance metrics/.

\subsection{Significant Metrics for Measuring Performance}

The focus of this project was to define energy performance metrics and establish procedures for measuring and reporting these metrics. We focused our efforts on six aspects of energy performance evaluation, which were developed into six procedures and technical documents. The technical areas were defined jointly by NREL and DOE as relevant to the energy performance of the building. A brief description of the six documents follows.

\section{Procedure to Measure Building Energy Performance}

The purpose of this procedure is to establish a standard method for monitoring and reporting on the energy performance of commercial buildings. It determines the energy consumption, electrical energy demand, and on-site energy production in commercial buildings of all types for the facility and end uses. The performance metrics determined here may be compared against benchmarks to evaluate performance and verify that performance targets have been achieved. Uses may include:

- Compare performance with the design intent.

- Compare performance with other buildings.

- Evaluate building performance rating systems.

- Perform economic analysis of energy-efficient strategies in buildings.

- Establish long-term performance records that enable maintenance staff to monitor trends in energy performance.

This procedure includes definitions of the performance metrics obtained, detailed steps for quantifying performance, and a list of suggested monitoring equipment (Barley et al. 2005).

\section{Procedure to Measure and Report the Performance of Photovoltaic Systems}

This procedure provides a standard method for measuring and characterizing the long-term energy performance of photovoltaic (PV) systems in buildings and the resulting implications to the building's energy use. The performance metrics determined here may be compared against benchmarks for evaluating system performance and verifying that performance targets have been achieved. Uses may include comparison of performance with the design intent, comparison with other PV systems in buildings, economic analysis of PV systems in buildings, and the establishment of long-term performance records that enable maintenance staff to monitor trends in energy performance (Pless et al. 2005). 


\section{Procedure to Measure Indoor Lighting Performance}

This document provides standard definitions of performance metrics and methods to determine them for the energy performance of building interior lighting systems. It can be used for existing or proposed buildings. Typical results from the use of this procedure are the monthly and annual energy used for lighting, energy savings from occupancy or daylighting controls, and the percent of the total building energy use that is used by the lighting system. The document was not developed specifically for retrofit applications. However, it does complement Measurement and Verification (M\&V) protocols that do not provide detailed performance metrics or measurement procedures (Deru et al. 2005).

\section{Procedure to Determine Source Energy and Emissions for Energy Use}

This procedure provides the fuel and emission factors to calculate the source (primary) energy and emissions for electricity, fuels, and thermal energy delivered annually to a facility, and combustion of fuels at a facility. The fuel and emission factors provided in this procedure account for the energy and emissions associated with extracting, processing, and delivering the fuels to the electrical power plants or directly to the buildings. In addition, the breakdown of the fuel used to generate electricity is provided on a national level, three interconnection levels, and the state level for Alaska and Hawaii (Deru and Torcellini 2005a).

\section{Standard Definitions of Building Geometry for Energy Evaluations}

This document provides definitions and metrics of building geometry for use in building energy evaluation. Building geometry is an important input in the analysis process, yet there are no agreed-upon standard definitions of these terms for use in energy analysis. The metrics can be used for characterizing building geometry, for calculating energy performance metrics, and for conducting energy simulations (Deru and Torcellini 2005b).

\section{Procedure to Develop a Baseline Simulation Model}

This procedure provides a standard method for developing a baseline simulation model of a minimally code-complaint commercial building for the purposes of whole-building energy simulations. It provides various classifications of baselines based on the design and operation status of the building under construction. Three major baselines are defined: Pre-Design, Proposed Design, and Existing Building. The procedure also tells users how to use each of these three baselines with an integrated design process (Pless, Deru, and Torcellini 2005).

\subsection{Work with Related Activities}

Throughout the Performance Metrics Research Project, we actively sought out related activities and tracked their progress. There are two benefits for seeking out other activities. First, we remain up to date with the current research and monitoring approaches. Second, sharing our efforts will help to improve their products and promotes a wider spread adoption of our products.

\section{ASHRAE Standards Project Committee 105}

Standards Project Committee (SPC) 105 is revising ASHRAE Standard 105 - Standard Methods of Measuring and Expressing Building Energy Performance. Michael Deru is a voting committee member. We assisted in most of the revision to ensure that the new document is consistent with the NREL Performance Metrics Research Project. The title of the revised standard is Standard Methods of Measuring, Expressing, and Comparing Building Energy 
Performance. The new standard will provide limited guidance on how to compare building energy performance with another building or with a group of buildings. The new standard is expected to be completed by July 2006.

\section{ASHRAE Standards Project Committee 100}

SPC 100 is revising ASHRAE Standard 100 - Energy Conservation in Existing Buildings. Michael Deru is a committee member. Michael Deru reviewed the proposed revisions and offered comments to ensure consistency between Standard 100, Standard 105, and the NREL Performance Metrics Research Project. Involvement in this task ensures that the revised Standard 100 and the NREL performance metrics use similar approaches and terminology. The new standard is expected to be completed by February 2006.

\section{ASHRAE Research Projects 1286 and 1092}

ASHRAE research project 1286-TRP is titled Evaluation of Building Energy Performance Rating Protocols and 1092-TRP is titled Development of Procedures to Determine In-Situ Performance of Commonly Used HVAC Systems. Michael Deru is the chair of the Project Monitoring Subcommittee (PMS) for 1286-TRP. Involvement in 1286-TRP provides a review of building rating procedures and allows NREL to help guide this research to help answer some of the important questions in this area. Keeping track of 1092-TRP provides updates on current research in measuring HVAC system performance.

\section{Green Building Challenge}

The Green Building Challenge (GBC) is an international display of high performing buildings and is led by the International Initiative for Sustainable Built Environment (iiSBE). They developed the revised framework and rating tool (GBTool) used for the GBC in 2005. NREL subcontractor Joel Ann Todd was closely involved in creating the new assessment framework and performance-rating tool. NREL has provided technical review and feedback on performance metrics and rating methods to ensure that they properly address the energy performance and use performance metrics and terminology that is consistent with the Performance Metrics Research Project. In addition, we learned from some of the international thinking in building performance evaluation.

\section{ASTM E06.71 Performance of Buildings - Sustainability}

The Sustainability subcommittee has seven active task groups (TGs). The groups with efforts related to performance metrics activities are Terminology, Building, and General Principles. Michael Deru is a member of the E06.71 subcommittee and attended three committee meetings. The effort outside of the meetings has been limited to reviewing documents and providing definitions for the Terminology TG. The Terminology standard is under continuous maintenance and has a few terms that are related to building energy performance. The General Principles TG is producing a new document that has undergone several drafts. We put in a small effort to keep track of the major changes and provided input to areas related to building energy performance. Involvement with this activity was kept small because there was a limited benefit to the Performance Metrics Research Project and because of time and cost constraints. 


\section{International Standards Organization TC59/SC17 Sustainability (ASTM E06.92.17)}

ASTM is the U.S. technical activity group (TAG) for the International Standards Organization (ISO) TC59/SC17 on Building Sustainability. The ISO subcommittee is preparing five documents related to building sustainability. The most relevant documents to DOE efforts are the Framework for Assessment of Environmental Performance of Buildings and Sustainability Indicators. Michael Deru is a member of the U.S. TAG. We reviewed early drafts of these documents and supplied comments. Involvement with this activity allowed the Performance Metrics Research Project to influence the international standards to use the same terminology and processes used in our work, and it provided the project with access to current efforts in other countries. Involvement with this activity was limited because the benefit to the Performance Metrics Research Project did not justify the required time and cost.

\section{Federal Energy Management Program}

The Federal Energy Management Program (FEMP) developed a set of protocols for quick assessment of the sustainability of buildings. NREL provided technical assistance in the preparation of the protocols to ensure that the energy features were handled in a manner that is consistent with the performance metrics approach. Version 1 of these protocols has been created and will be tested with sets of two buildings in Fort Lewis and in several Navy buildings. All of the tests will be conducted with two or more buildings that are similar except that one is newer with more "sustainable" features (Fowler et al. 2005a, 2005b).

\section{High-Performance Buildings Database}

The High Performance Building Initiative at NREL has created a Web-interactive database of buildings that incorporate high-performance features. The Performance Metrics Research Project at NREL provided technical assistance to BuildingGreen in the development of new energy pages for the database. The new energy pages are consistent with the Performance Metrics Research Project and lessons learned from the first two years of database operation. The database is currently supported by the following end-users: BuildingGreen, FEMP, U.S. Green Building Council (USGBC), American Institute of Architects, Massachusetts Technology Collaborative (MTC), Cascadia Chapter of USGBC, and Efficiency Vermont. These organizations are using the database to display case studies of their projects. Ensuring that the energy metrics are consistent with the performance metrics procedures will add consistency to the database and provide exposure for the performance metrics activity. In addition, MTC will use the performance metrics procedures in its projects. MTC is training energy-monitoring teams to use the performance metrics procedures.

\section{Facilities Performance Evaluation Group}

An interagency group of U.S. and Canadian federal and U.S. state agencies formed a working group called Facilities Performance Evaluation (FPE). The FPE group provided input to the Performance Metrics Research Project team on current methods used for measuring building energy performance. NREL worked with this group to clearly define its needs and to improve its energy monitoring procedures and performance metrics. 


\section{Conclusions and Recommendations}

The building industry uses many approaches to assess the energy performance of buildings with very little standardization. This disparity makes it difficult to understand the real energy performance of buildings and to transfer knowledge from one activity to another. Standardized metrics are useful for evaluating research and research programs. This includes consensus on what performance metrics are important, the appropriate reference cases, and methods of reporting.

This project has created a starting point with a set of performance measures. We have created standards for evaluation and reporting efforts with clearly defined performance metrics and procedures for determining them. By using these performance metrics and evaluation methods, we will enhance sharing of information between researcher projects and improve how we track progress toward our energy saving goals. The work completed in this project is already being used in NREL research and will directly support the following NREL research efforts in fiscal year 2006:

- Design Guide Development (Task 1): The simulation work for the design guideline will use the baseline procedure and benchmark buildings (Task 4) to establish the starting points for energy simulations. The performance metrics from the whole-building procedure will be used to measure progress toward the energy saving goals.

- Validation of Design Technologies (Task 1): This task will require monitoring and evaluation of the design technologies in real buildings, which will be conducted in accordance to the appropriate procedures developed in the Performance Metrics Research Project.

- Optimization (Task 2): This task will use the baseline procedure and benchmark from Task 4 as starting points and the performance metrics from the whole-building procedure to measure progress. The fuel and emissions factors may also be used to better understand the environmental impact of the optimization pathways. It will report results based on the established performance metrics.

- High Performance Buildings Database (Task 3): The energy performance metrics used in the High-Performance Buildings database were created from the work in the Performance Metrics Research Project.

- Benchmark (Task 4): This task will use the baseline procedure as a starting point for defining the benchmark buildings.

This project has provided clarity in an area that has been the source of many misunderstandings and confusion. There remains further work in this and related areas. Although this project has been completed, other aspects of measuring and reporting building energy performance that remain to be addressed with possible future research include:

- Zero-energy buildings (ZEBs): There are several definitions for zero-energy building, and there is very little understanding of how zero-energy or net energy producing buildings (NEPB) affect the electricity grid and utility companies. These buildings typically have low energy use but high demand, which can be problematic for utilities. In addition, we don't know how energy-producing buildings affect hourly source energy and emissions. There is a research need to determine the potential affects of large numbers of 
ZEBs and NEPBs on the electricity grid and how to manage the demand through controls and on-site energy storage.

- Tracking performance over the life of a building: The energy performance of many new buildings is not as expected from the design phase and degrades further after the first few years. Poor performance usually goes unnoticed because no easy methods of measuring and tracking performance exist. Simple methods of monitoring and tracking the energy performance by end use in buildings are needed.

- Rating performance: Everyone who measures the energy use in buildings wants to know how well the building is performing. There are many methods of rating performance or benchmarking and they often give different results. Some of the methods are simple and some require experienced professionals. It is important to understand the meanings and limitations of the results. There is a need for a relatively simple method that can provide results that are easily compared with the results of other buildings. ENERGY STAR provides one approach that compares the building to a database of existing buildings. This method does not tell the user how well the building might perform. A simple webbased simulation tool could provide users with a comparison with a code-compliant building and offer suggestions on how to improve the energy use.

- HVAC component performance metrics: There are many good metrics and procedures for HVAC components, but they are from many different sources. A central source of HVAC performance metrics would provide easy source for practitioners with consistent definitions and approaches.

- Delivered HVAC system performance: Many approaches measure and define HVAC system performance; however, the methods and definitions are generally not standardized. The exception to this statement is ASHRAE Guideline 14, which provides methods for measuring, analyzing, and reporting the energy savings of retrofits to building energy systems.

- Life-cycle analysis (LCA) of buildings: Buildings consume more than one-third of our source energy, more than $70 \%$ of the electricity, and a large percentage of our natural resources. As the building operating energy goes to zero, the embodied energy becomes very important. LCA provides a mechanism to weighing different aspects of a building. This weighing is needed to help make design decisions in creating the most environmentally friendly buildings possible. LCA provides a method to determine the environmental impacts over the life of a building. The USGBC is in the process of incorporating LCA into its LEED rating systems. However, only two tools are available in the United States for conducting LCAs on buildings, and they do not answer all the questions. The U.S. LCI Database at NREL establishes the basic information for LCA of buildings, but more work needs to be done to provide the necessary tools for designers and builders to reduce the overall environmental impact of buildings.

- Energy simulation of existing buildings: This can be a useful tool for understanding their energy performance and exploring ways of improving their performance. However, it is difficult to prepare a good simulation model of an operating building. There is very little formal guidance on how to prepare and calibrate a building simulation model. 


\section{References}

ASHRAE (1999). Standard Methods of Measuring and Expressing Building Energy

Performance. ANSI/ASHRAE Standard 105-1984 (RA 99). Atlanta, GA: American Society of Heating, Refrigerating and Air-Conditioning Engineers, Inc.

ASHRAE (2002). Measurement of Energy and Demand Savings. ASHRAE Guideline 14-2002. Atlanta, GA: American Society of Heating, Refrigerating and Air-Conditioning Engineers, Inc.

ASHRAE (2003). ASHRAE GreenGuide. Atlanta, GA: American Society of Heating, Refrigerating and Air-Conditioning Engineers, Inc.

ASHRAE (2004a). Advanced Energy Design Guide For Small Office Buildings. Atlanta, GA: American Society of Heating, Refrigerating and Air-Conditioning Engineers, Inc.

ASHRAE (2004b). Procedures for Commercial Building Energy Audits. Atlanta, GA:

American Society of Heating, Refrigerating and Air-Conditioning Engineers, Inc.

Barley, C.D.; Deru, M.; Pless, S.; Torcellini, P. (2005). Procedure for Measuring and Reporting Commercial Building Energy Performance. Technical Report NREL/TP-550-38601. Golden, CO: National Renewable Energy Laboratory. www.nrel.gov/publications/.

BRE (2005). BREEAM Building Research Establishment Environmental Assessment Method. Watford, UK: Building Research Establishment. http://www.breeam.org/. Accessed September 2005.

Deru, M.; Todd, J.A. (2004). Review of Building Energy Performance Metrics. Golden, CO:

National Renewable Energy Laboratory.

Deru, M.; Torcellini, P. (2004). Improving Sustainability of Buildings through a PerformanceBased Design Approach. A.A.M. Sayigh, ed. Proceedings of the World Renewable Energy Congress VIII (WREC 2004), 29 August-3 September 2004, Denver, Colorado (CD-ROM). [Amsterdam]: Elsevier, Ltd.; Monterey, CA: Produced by InControl Productions, Inc.; 8 pp.; NREL Report No. CP-550-36276. www.nrel.gov/docs/fy04osti/36276.pdf

Deru, M.; Blair, N.; Torcellini, P. (2005). Procedure to Measure Indoor Lighting Energy Performance. Technical Report NREL/TP-550-38602. Golden, CO: National Renewable Energy Laboratory. www.nrel.gov/publications/.

Deru, M.; Torcellini, P. (2005a). Procedure to Determine Source Energy and Emissions for Energy Use in Buildings. Technical Report NREL/TP-550-38617. Golden, CO: National Renewable Energy Laboratory. www.nrel.gov/publications/.

Deru, M.; Torcellini, P. (2005b). Standard Definitions of Building Geometry for Energy Evaluation Purposes. Technical Report NREL/TP-550-38600. Golden, CO: National Renewable Energy Lab. www.nrel.gov/publications/. 
DOE (2000). High-Performance Commercial Buildings: A Technology Roadmap. Washington D.C.: U.S. Department of Energy. www.eere.energy.gov/buildings/info/documents/pdfs/roadmap lowres.pdf. Accessed August 2005.

EPA (2005). ENERGYSTAR Portfolio Manager. Washington, D.C.: Environmental Protection Agency. http://www.energystar.gov. Accessed August 2005.

Flanders, L. (2000). Assistant Director (UN Division for SD) at the conference Sustainable Development of Coastal Zones and Instruments for its Evaluation, Germany, 23-26 Oct. 2000.

Fowler, K.M.; Solana, A.E.; Spees, K. (2005a). Building Cost and Performance Metrics: Data Collection Protocol. Revision 1.0. Richland, WA: Pacific Northwest National Laboratory.

Fowler, K.M.; Solana, A.E.; Spees, K. (2005b). Building Cost and Performance Metrics: Data Collection Field Guide. Revision 1.0. Richland, WA: Pacific Northwest National Laboratory.

Haberl, J.; Lopez, R.; and Sparks, R. (1992). LoanSTAR Monitoring and Analysis Program: Building Energy Monitoring Workbook. Energy Systems Laboratory Report No. ESL-TR-92/0603, College Station, TX: Texas A\&M University.

Haberl, J.; Reddy, T.; Claridge, D.; Turner, D.; O'Neal, D.; and Heffington, W. (1996). Measuring Energy-savings Retrofits: Experiences from the Texas LoanSTAR Program, Energy Systems Laboratory, Texas A\&M University. ORNL/Sub/93-SP090/1, Oak Ridge, TN: Oak Ridge National Laboratory.

IPMVP (2005). International Performance Monitoring and Verification Protocols. www.ipmvp.org. Accessed September 2005.

LBNL (2005). CALARCH, California Building Energy Reference Tool. Berkeley, CA: Lawrence Berkeley National Laboratory. http://poet.lbl.gov/cal-arch/benchmark.html Accessed September 2005.

Merriam-Webster On-Line Dictionary. http://www.m-w.com/home.htm. Accessed January 2004.

PCSD (1999). U.S. Interagency Working Group on Sustainable Development Indicators, Council on Environmental Quality. Presidents Council on Sustainable Development Final Report http://clinton4.nara.gov/textonly/PCSD/index.html. Accessed August 2005.

Pless, S.; Deru, M.; Torcellini, P. (2005). Procedure for Developing a Baseline Simulation Model for a Minimally Code Compliant Commercial Building. Technical Report NREL/TP-55038604. Golden, CO: National Renewable Energy Laboratory. http://www.nrel.gov/publications/.

Pless, S.; Deru, M.; Torcellini, P.; Hayter, S. (2005). Procedure for Measuring and Reporting the Performance of Photovoltaic Systems in Buildings. Technical Report NREL/TP-550-38603. Golden, CO: National Renewable Energy Laboratory. www.nrel.gov/publications/.

USGBC (2005). Leadership in Energy and Environmental Design. Washington, D.C.: U.S. Green Building Council. http://www.usgbc.org/. Accessed August 2005. 


\section{Appendix - Metrics Terminology}

In our review of the state-of-the-science in building performance evaluation, we discovered that some of the most commonly used terms do not have common definitions. This disparity in how terms are used adds to the confusion in this field. We compiled the following list of definitions from common practice and the Merriam-Webster Dictionary for use in this project.

Baseline - a standard reference case or condition used as a basis for comparison

Examples: a simulation model of a ASHRAE 90.1 compliant building, a control building, measurement of energy consumption before an energy conservation measure is applied.

Comments: Establishing a clearly defined baseline is important and defining a repeatable baseline is essential if the work is to be compared to results of other work.

Benchmark - (noun) a standardized problem or test case that serves as a basis for evaluation or comparison (Merriam-Webster 2004). (verb) The comparison of a performance aspect to a standard test case.

Examples: For noun examples, see Baseline. Examples of Benchmark used as a verb include the use of ENERGY STAR for buildings (EPA 2005) and the LEED energy credits (USGBC 2005).

Comments: The terms benchmark (noun) and baseline are often used interchangeably; however, we use baseline in this project. Consistent and repeatable benchmarking requires clearly defined performance metrics and protocols for developing the reference case to serve as the baseline.

Building Performance Index - (BPI) A high level indicator of the performance of a building

Examples: BPI is often used to refer to the energy use intensity.

Comments: There is no standard definition of this term. It is sometimes used to refer to the energy use intensity and sometimes used to combine different factors (energy, environmental, economic, etc.) into one term. This term is not used in this project at this time because it is not specific and can lead to confusion.

Design Guideline - a set of rules and strategies to help building designers meet certain performance criteria such as energy efficiency or sustainability

Examples: AHSRAE Green Guide (ASHRAE 2003), ASHRAE Advanced Energy Design Guides (ASHRAE 2004a), LEED (USGBC 2005), and BREEAM (BRE 2005).

Comments: Although LEED and BREEAM are technically rating systems, they are often used as design guidelines.

Energy Audit - A systemized approach to measuring, recording, and evaluating the operating performance of a building or building system with the intention of improving the energy performance

Examples: Procedures for Commercial Building Energy Audits (ASHRAE 2004b)

Comments: The performance metrics and procedures from this project were not developed specifically for energy audits; however, energy audits can benefit greatly from the use of standard performance metrics as defined in this project.

Index - a number (as a ratio) derived from a series of observations and used as an indicator or measure (Merriam-Webster 2004)

Examples: Consumer price index

Comments: An index is usually taken as a percentage. 
Indicator - a parameter, or a value derived from a set of parameters, that points to, provides information about, or describes the state of a phenomenon. It has significance beyond that directly associated with the parameter value (Flanders 2000).

Examples: Global warming potential

Comments: "Indicators are one of many tools for simplifying, quantifying, and communicating vast amounts of information in ways that are more easily understood. They are also useful for alerting us to what areas that need more attention, as well as areas that see improvement." (PCSD 1999).

Measurement and Verification - $(\mathrm{M} \& \mathrm{~V})$ the process of examining and proving the results of implementing strategies toward achieving a goal

Examples: International Performance Measurement and Verification Protocol, ASHRAE Guideline 14

Comments: In the context of buildings, $\mathrm{M} \& \mathrm{~V}$ is typically used to validate that projected savings are achieved for energy and water conservation measures.

Metric - a standard definition of a measurable quantity

Examples: area, insolation

Comments: A performance metric is a metric of some performance characteristic; however, not all metrics are performance metrics. For example, area is a metric, but it is not a performance metric.

Performance Goal - a specific statement of a desired level of achievement

Examples: Reduce annual building source energy consumption by $10 \%$ compared to year 2000 .

Comments: Performance goals must be measurable and definite such that progress can be evaluated. Performance metrics should be carefully chosen to measure progress toward performance goals.

Performance Index - a number (as a ratio) derived from a series of observations and used as an indicator or measure

Examples: Building Performance Index, Energy Cost Index

Comments: A performance index can be a primary or a secondary level performance metric. Performance index is not used in this project to avoid introducing more terms than are necessary.

Performance Indicator - a high-level performance metric that is used to simplify complex information and point to the general state or trends of a phenomenon

Examples: Average Building Energy Use Intensity for all office buildings, Number of Buildings with Daylighting Controls

Comments: Performance indicators are used to communicate general trends and are often used on a program planning level to show progress toward goals. See the definition of indicator for more discussion.

Performance Metric - a standard definition of a measurable quantity that indicates some aspect of performance

Examples: Building Energy Use Intensity (BEUI), Net PV System Production, and Lighting Power Density 
Comments: Performance metrics should measure and communicate progress toward achieving performance goals. There are different levels of performance metrics. The Performance Metrics Research Project is generally concerned with the primary level, which is the lowest level. The primary level performance metrics are applicable to a specific project, such as the BEUI and end-use energy break down. Secondary performance metrics are often combinations of lower level performance metrics and other data, and they are used to show performance of a group of buildings or across an entire building category. An example of a secondary performance metric would be the gross energy intensity of a group of office buildings.

Performance Objective - a general statement of a desired achievement

Examples: Reduce building energy consumption, reduce emissions related to building operation.

Comments: Performance goals are specific statements of performance objectives.

Procedure - a standard method or set of methods for determining one or more performance metrics

Examples: Procedure for Measuring and Reporting Commercial Building Energy Performance, Procedure for Measuring and Reporting the Performance of Photovoltaic Systems in Buildings

Comments: This is one of the primary products of the Performance Metrics Research Project.

Protocol - a detailed plan of a scientific or medical experiment, treatment, or procedure (MerriamWebster 2004)

Examples: International Performance Measurement \& Verification Protocol

Comments: Protocol is often used interchangeably with procedure; however, protocol usually infers something that is officially recognized as a standard. It is a procedure that has widespread review and acceptance.

Rating System - a system of rules for comparing the performance of a whole-building or building system to benchmarks

Examples: ENERGY STAR for Buildings (EPA 2005), CalArch (LBNL 2005), LEED (USGBC 2005), and BREEAM (BRE 2005)

Comments: Some rating systems, such as ENERGY STAR, are designed to rate the measured energy performance of existing buildings, and some, such as LEED, are designed to rate the expected performance during the design stage. In addition, LEED and BREEAM are environmental rating systems and energy is only one part of the rating. One point of confusion is that LEED is often used as a design guide. 


\section{REPORT DOCUMENTATION PAGE}

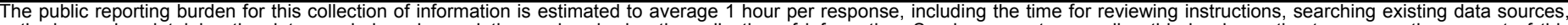

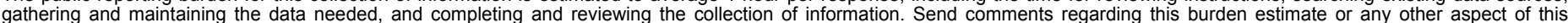

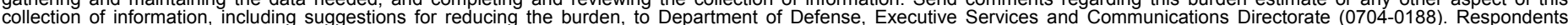

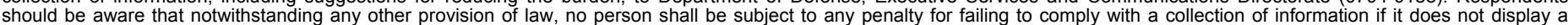

currently valid OMB control numbe

PLEASE DO NOT RETURN YOUR FORM TO THE ABOVE ORGANIZATION.

\section{REPORT DATE (DD-MM-YYYY) \\ October 2005 \\ 2. REPORT TYPE \\ Technical report}

4. TITLE AND SUBTITLE

Performance Metrics Research Project - Final Report
3. DATES COVERED (From - To) 2004-2005

5a. CONTRACT NUMBER

DE-AC36-99-G010337

5b. GRANT NUMBER

5c. PROGRAM ELEMENT NUMBER

5d. PROJECT NUMBER

NREL/TP-550-38700

5e. TASK NUMBER

BEC3.3003

5f. WORK UNIT NUMBER
7. PERFORMING ORGANIZATION NAME(S) AND ADDRESS(ES)

National Renewable Energy Laboratory

1617 Cole Blvd.

Golden, CO 80401-3393
8. PERFORMING ORGANIZATION REPORT NUMBER

NREL/TP-550-38700

9. SPONSORING/MONITORING AGENCY NAME(S) AND ADDRESS(ES)

10. SPONSOR/MONITOR'S ACRONYM(S) NREL

11. SPONSORING/MONITORING AGENCY REPORT NUMBER

12. DISTRIBUTION AVAILABILITY STATEMENT

National Technical Information Service

U.S. Department of Commerce

5285 Port Royal Road

Springfield, VA 22161

13. SUPPLEMENTARY NOTES

14. ABSTRACT (Maximum 200 Words)

NREL began work for DOE on this project to standardize the measurement and characterization of building energy performance. NREL's primary research objectives were to determine which performance metrics have greatest value for determining energy performance and to develop standard definitions and methods of measuring and reporting that performance.

\section{SUBJECT TERMS}

performance metrics; building energy analysis; commercial buildings; building energy performance; energy performance; energy performance benchmarks; energy analysis procedure; high-performance buildings

\begin{tabular}{|c|c|c|c|c|}
\hline \multicolumn{3}{|c|}{ 16. SECURITY CLASSIFICATION OF: } & \multirow{2}{*}{$\begin{array}{l}\text { 17. LIMITATION } \\
\text { OF ABSTRACT } \\
\text { UL }\end{array}$} & \multirow{2}{*}{$\begin{array}{ll}\text { 18. } & \text { NUMBER } \\
\text { OF PAGES }\end{array}$} \\
\hline $\begin{array}{l}\text { a. REPORT } \\
\text { Unclassified }\end{array}$ & $\begin{array}{l}\text { b. ABSTRACT } \\
\text { Unclassified }\end{array}$ & $\begin{array}{l}\text { c. THIS PAGE } \\
\text { Unclassified }\end{array}$ & & \\
\hline
\end{tabular}

9b. TELEPHONE NUMBER (Include area code) 